\title{
An infrequent response to slit-lamp examination
}

\author{
I. LEWKONIA
}

Moorfields Eye Hospital, London, W.C.I

"Sneezing may be defined as a spasmodic expiration preceded by one or more spasmodic inspirations" (Brubaker, I9I9). Many conditions are capable of inducing a sneeze (Yater and Oliver, I96I), but of particular interest to the ophthalmologist is the production of sneezing in response to light. The term "photic sneeze reflex" has been used by Everett (1964) to distinguish this form of stimulus from others which produce the response.

Light-induced sneezing appears to be a relatively common occurrence. Everett (1964) found a definite history of it in 68 out of 414 individuals ( $16 \cdot 4$ per cent.). He reported it to be commoner in the male than in the female, commoner in the Caucasian than in the Negro, and commoner in those with a family history of light-induced sneezing. He found no significant correlation with any allergic condition.

The usual source of stimulation in susceptible individuals is sunlight, but artificial light may also initiate the reflex. Sédan (1954) described the reflex in patients exposed to such varying stimuli as sunlight, the ophthalmoscope beam, photographic flash, and ultraviolet light. Boudouresques (1950) stated that a white wall or a bright colour may also induce the reflex, while ocular disease, particularly keratitis, may also sometimes be present (Watson, 1875; Boudouresques, 1950). Everett and Sédan were impressed by the observation that the sneezing usually occurred only at the onset of exposure to light after which there follows a refractory period when further sneezing cannot be elicited. Everett considered the physiological basis for the reflex, and in particular suggested that "parasympathetic generalization" may be a possible explanation. By this is meant the excitation of one structure innervated by the parasympathetic nervous system following the stimulation of another similarly innervated structure. Applying this hypothesis to the photic sneeze reflex, the parasympathetic activity of pupillary constriction (N III) brought about by exposure to light would produce congestion and secretion of the nasal mucosa (N VII) in susceptible individuals, factors which are known to initiate sneezing.

The main purpose of this paper is not to speculate further about the mechanism of the reflex, but to draw attention to yet another method of eliciting it, namely by slit-lamp examination of the eye. Although such an examination would seem to be an easy way of producing the reflex in susceptible individuals, it does not appear to have been previously described in the literature, perhaps because of a failure to recognize the explosive outburst as a manifestation of this light-stimulation-induced reflex.

\section{Case report}

A man aged 47 was transferred on July 17, 1968, to Moorfields Eye Hospital, High Holborn, from hospital in Persia, with the history that 8 days previously he had suffered injury when potassium hydroxide splashed into both eyes. Immediately after the accident, he was treated by irrigation of 
the eyes and frequent instillations of mydriatics and local antibiotic drops and ointment. Whe first seen here the unaided visual acuity was $6 / 60+\mathrm{I}$ in the right eye and $6 / 24$ in the left. Ther was extensive sloughing of the corneal epithelium and of the bulbar conjunctiva of both eyes. Locaळ treatment with mydriatics and antibiotics was continued. In addition a short course of systemi antibiotics followed by a more prolonged course of systemic steroids was prescribed. Progress wa slow, but eventually the epithelium healed and additional treatment with local steroid drops wa commenced, with good effect. The stroma of both corneae, however, remained oedematous anc with the appearance of superficial and deep corneal vascularization local radiotherapy becamల్థ necessary. This arrested the vascular ingrowth.

There was little of importance in the patient's general medical history, as apart from rheumatie fever 20 years previously he had suffered from only minor ailments. There was no history of nasab disease or hay fever. He was known to be allergic only to barbiturates, which produced a drug. eruption when formerly administered.

While an in-patient, it was noticed that he frequently sneezed when a bright light was directe $\frac{\mathbb{P}}{0}$. towards his eyes, particularly during ophthalmoscopic and slit-lamp examination. At the time of his discharge from hospital, it was decided to keep a record of his sneezing in response to subsequent examinations with the slit lamp. Initially he was seen daily and the frequency of sneezing is indif cated in the accompanying Table.

Table Frequency of sneezing per visit

\begin{tabular}{|c|c|c|c|c|c|c|c|c|c|c|c|c|c|c|c|}
\hline lisit no. & 1 & 2 & 3 & 4 & 5 & 6 & 7 & 8 & 9 & 10 & I I & 12 & 13 & 14 & 15 \\
\hline No. of sneezes & 2 & 3 & 2 & o & 3 & o & 2 & 0 & I & o & o & o & 0 & o & I \\
\hline
\end{tabular}

Later, the patient was directly questioned about his susceptibility to sneezing. He recalled tha since childhood he had frequently sneezed after exposure to a variety of bright lights, includingu sunlight. He was not aware of any other unusual stimuli which induced sneezing, nor was iळ possible to demonstrate any on examination. He offered the information that his mother wa

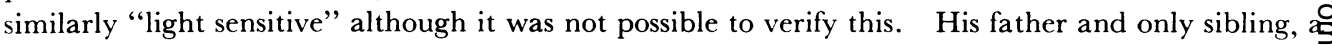
brother, were "non-sneezers".

\section{Comment}

Before each examination, the patient waited in a room illuminated by ordinary dayligh and artificial lighting. None of the examinations was unduly prolonged and unlike thosi quoted by Everett and Sédan this patient never sneezed at the beginning of the examina tion. The sneezing usually occurred later on, when the irritable, photophobic eyes wereg lacrimating profusely. Moreover, the patient did not demonstrate the refractory period previously mentioned. Indeed when the sneezing was repeated, the outbursts usually followed each other in quick succession. It is interesting to note that the repeated attackso of sneezing occurred soon after the patient was discharged from hospital and that as then eyes became less irritable, the sneezing became less frequent. This would suggest that the production of sneezing was directly associated with the more profuse lacrimation in the early stages of recovery, perhaps by virtue of a reflex-stimulating action of the tears on theo lacrimal passages and nasal mucosa. The delay in the onset of sneezing following exposure⿻⿱⺈口⺕中 to light can be regarded as the time taken for the tears to pass along the lacrimal passages to the nasal mucosa before initiating the reflex.

Since preparing this paper another patient who manifests the "photic sneeze reflex" on slit-lamp examination has been brought to my attention. She attended at Moorfields $s_{\stackrel{\mathbb{D}}{\mathbb{Q}}}$ Eye Hospital having noticed some reduction in visual acuity in both eyes. She was found 
to have early senile lens opacities without evidence of any other ocular disease. Examination with the slit lamp produced sneezing. She was noticed to have blue irides, a predisposing factor in the production of photophobia. This was the only feature which could be incriminated to account for her response.

\section{Summary}

A description is given of the "photic sneeze reflex" and of its presence in two patients. Although the reflex is well known, its production by slit-lamp examination does not appear to have been specifically noted previously. It is suggested that lacrimation may be an important factor in mediating the reflex in certain individuals.

I wish to thank Mr. Ian Duguid for his assistance in preparing this paper and for permission to describe two of his patients.

\section{References}

Boudouresques, J. (1950) "Encyclopédie médico-chirugicale (Nervous system)", i 7012 E, p. I brubaker, A. P. (1919) 7. Amer. med. Ass., 73, 585

EVERETT, H. C. (1964) Neurology (Minneap.), 14, 483

sÉDAN, J. (1954) Rev. Oto-neuro-ophtal., 26, 123

watson, w. s. (1875) "Diseases of the Nose and Its Accessory Cavities", p. 343. Lewis, London YATER, w. M., and oliver, W. F. (196I) "Symptom Diagnosis", 5th ed., p. 184. Appleton-Century-

Crofts, New York 